\title{
Common Bile Duct Cysts Leading to Cholestasis and Jaundice: A Rare Case Report
}

\author{
El Mahdi Benkoukous ${ }^{1}$, Pierlesky Elion Ossibi ${ }^{1}$, Zacharia Traore², El Bachir Benjelloun1, \\ Saeed Abdul-Razak ${ }^{1}$, Kassim Sidibe ${ }^{2}$, Youssef Lamrani², Abdelmalek Oussaden ${ }^{1}$, \\ Khalid Mazaz' ${ }^{1}$ Khalid Ait Taleb ${ }^{1}$ \\ ${ }^{1}$ Department of Visceral Surgery, Hassan II Teaching Hospital, Fes, Morocco \\ ${ }^{2}$ Department of Radiology, Hassan II Teaching Hospital, Fes, Morocco \\ Email: "Mahdi.benkoukous@gmail.com
}

Received 26 May 2015; accepted 6 July 2015; published 9 July 2015

Copyright (C) 2015 by authors and Scientific Research Publishing Inc.

This work is licensed under the Creative Commons Attribution International License (CC BY). http://creativecommons.org/licenses/by/4.0/

cc) (i) Open Access

\begin{abstract}
Cystic dilatation of the common bile duct constitutes a rare congenital malformation prevalent in people of Asian origin with a female predominance. Its classification follows that of Todani. The commonest form, found in $\mathbf{8 0} \%$ of cases, is type I. Common bile duct cysts are often diagnosed in 2 out of 3 cases, during childhood with adult forms often rare. We hereby report the case of a cystic dilatation of the bile duct in a 75-year-old patient without significant history of disease.
\end{abstract}

\section{Keywords}

Dilatation, Cyst, Common Bile Duct, Jaundice, Adult

\section{Introduction}

Cystic dilatation of the common bile duct represents a rare anomaly with few cases reported in the Far East [1]. This condition mostly affects young children. Adult forms are rare and correspond to lesions present during childhood hithertoundiagnosed or asymptomatic. This diagnostic term however encompasses several clinical and pathological variants, depending on the location, shape and distribution of cystic malformation. Its diagnosis is based largely on imaging: with ultrasonography-computerized tomography (CT) serving as first line diagnostic tools and especially magnetic resonance cholangio-pancreatography (MRCP) allowing precise analysis of biliary tree malformations and associated anomalies of the biliopancreatic junction. Thus, we report the case of a "Corresponding author.

How to cite this paper: Benkoukous, E.M., Ossibi, P.E., Traore, Z., Benjelloun, E.B., Abdul-Razak, S., Sidibe, K., Lamrani, Y., Oussaden, A., Mazaz, K. and Taleb, K.A. (2015) Common Bile Duct Cysts Leading to Cholestasis and Jaundice: A Rare Case Report. Surgical Science, 6, 298-300. http://dx.doi.org/10.4236/ss.2015.67044 
75-year-old patient without any significant medical history who presents with cystic dilatation of the common bile duct diagnosed in an episode of jaundice confirmed on cholangio magnetic resonance imaging (MRI).

\section{Case}

Patient, 75 years old with no history of disease admitted to our unit for jaundice. History dates back to two months prior to his admission by the onset of jaundice associated with right upper quadrant pain with no other signs, no loss of general condition or fever.

Physical examination found a conscious patient with good vital signs a febrile with evident mucocutaneous jaundice and right upper quadrant tenderness.

Laboratory tests came back for cholestasis with Total Bilirubinat $71 \mathrm{mg} / \mathrm{l}$, direct bilirubin at $66 \mathrm{mg} / \mathrm{l}$, gamma-glutamyl transpeptidase $238 \mathrm{UI} / \mathrm{l}$, alkaline phosphatase $457 \mathrm{UI} / \mathrm{l}$, White blood count $4500 / \mathrm{mm}^{3}$, and C-Reactive Protein $10 \mathrm{mg} / \mathrm{l}$.

Abdominal ultrasound revealed cystic dilatation of the common bile duct and liver bile ducts.

Cholangio-MRI made evident a common bile ductcyst measuring $22 \mathrm{~mm}$ without any detectable gall stone or further obstacle downstream of the biliopancreatic junction (Figures 1(A)-(C)).

The treatment consisted of cholecystectomy coupled with choledochal cyst resection and a Roux-en-Y type hepaticojejunostomy anatomosis.

Histological examination of the surgical piece did not show any sign of malignancy.

The postoperative course was uneventful with good clinical evolution.

\section{Discussion}

Cystic dilatation of the bile duct remains a rare disease: with prevalence in the west ranging from $1 / 100,000$ to 1/200,000 births yet more frequent in the Far East [1]. It occurs more often in females and may be diagnosed at any age. However, it is essentially a pediatric affection as $75 \%$ of cases are often diagnosed before the age of 10 . [1].

It presents in two distinct clinical forms in children. First, a congenital form commonly associated with high levels of blood Conjugated bilirubin (Bc) in the first two years of life and a second variant, diagnosed later,

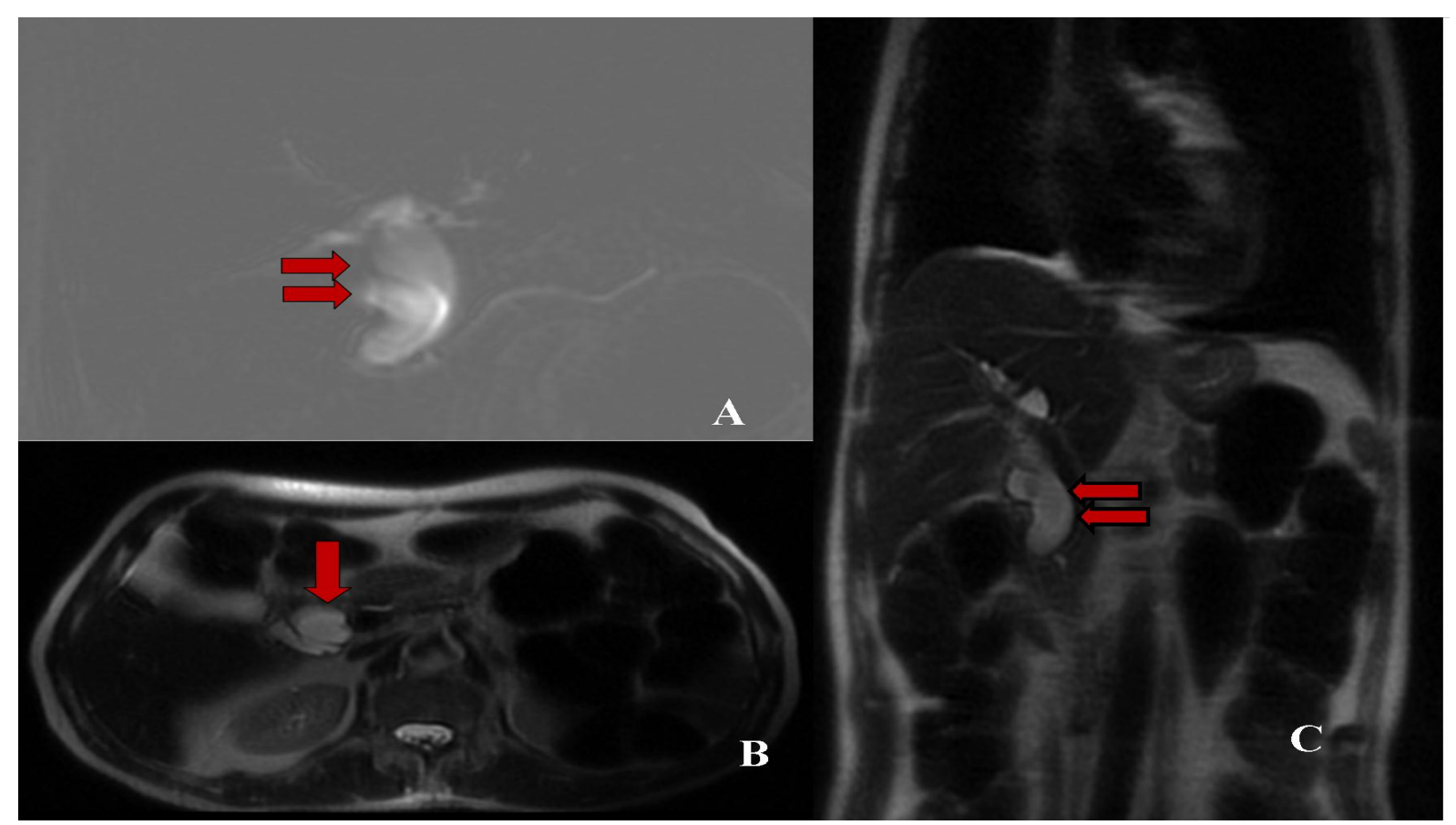

Figure 1. (A) Cholangio MRI Sequence showing dilatation of common bile duct; (B) Axial section showing cystic dilatation of common bile duct; (C) Coronal section showing cystic dilatation of common bile duct. 
which presents as the classical triad of abdominal pain, jaundice, and a palpable mass related in $20 \%-25 \%$ of patients [2].

In 1959, Alonso-Lej et al. [3] described three types of choledochal cysts. Approximately $85 \%-90 \%$ of cysts are Type I, which corresponds to a cystic dilatation of the common bile duct. Type II cysts appear as diverticular malformation of the common bile duct. Finally, the type III variant is described as a cystic dilatation of the distal portion of the common bile duct leading into the duodenal wall. Todani et al. in 1977 [4] revised the classification describing two types: type IV, which consists of multiple dilatations of the bile ducts both intra- and/or extra hepatic and type $\mathrm{V}$ which presents as a fusiform dilatations of the biliary tree termed Caroli disease when associated with liver fibrosis.

Laboratory tests are however inconclusive and non specific [5]. They may reveal cholestasis, an inflammatory syndrome with leukocytosis suggestive of infection.

The first line diagnostic imaging involves ultrasound, which usually shows a cystic lesion with CT usually confirming diagnosis. Cholangiography may allow a relatively refined analysis of the nature of the lesion all of which currently are gradually being replaced by Cholangio MRI.

Recommended treatment in adults and children entails cholecystectomy, lithotomy and especially cyst resection with roux-en You omega type biliary-enteric anastomosis [6].

In the absence of treatment its evolutionis usually marked by serious infectious complications, degenerescence and even death.

\section{Conclusion}

Cystic dilatation of the common bile duct is a rare malformation whose spontaneous progression may lead to serious infectious complications, degenerescence and death. This justifies early diagnosis and treatment by surgical cyst resection.

\section{References}

[1] Yamaguchi, M. (1980) Congenital Choledochal Cyst: Analysis on 1433 Patients in the Japanese Literature. The American Journal of Surgery, 140, 653-657. http://dx.doi.org/10.1016/0002-9610(80)90051-3

[2] Lopez, R.R., Pinson, W., Campbell, J.R., Harrison, M. and Katou, R.M. (1991) Variation on Management Bases on Type of Choledochal Cyst. The American Journal of Surgery, 161, 612-615. http://dx.doi.org/10.1016/0002-9610(91)90911-V

[3] Alonso-Lej, et al. (1959) Congenital Choledocal Cyst, with Report of 2, and Analysis of 94, Cases. International Journal of Surgery, 108, 1-30.

[4] Todani, T., Watanable, Y., Narusue, M., Tabuchi, K. and Okajima, K. (1977) Congenital Bile Duct Cysts: Classification, Operative Procedures, and Review of Thirty-Seven Cases Including Cancer Arising from Choledochal Cyst. The American Journal of Surgery, 134, 263-269. http://dx.doi.org/10.1016/0002-9610(77)90359-2

[5] Banerjee Jesudason, S.R., Ranjan Jesudason, M., Paul Mukha, R., Vyas, F.L., Govil, S. and Muthusami, J.C. (2006) Management of Adult Choledochal Cysts-A 15-Year Experience. The Official Journal of the International HepatoPancreato Biliary Association (Oxford), 8, 299-305.

[6] Ammori, J.B. and Mulholland, M.W. (2009) Adult Type I Choledochal Cyst Resection. Journal of Gastrointestinal Surgery, 13, 363-367. http://dx.doi.org/10.1007/s11605-008-0521-z 